\title{
Improving the quality of research into the health of migrant and ethnic groups
}

\author{
Marleen Foets
}

Received: 9 August 2011/Accepted: 15 August 2011/Published online: 27 August 2011

(C) Swiss School of Public Health 2011

Notwithstanding the political climate in Europe-uneasy because of new inflows of (illegal) asylum seekers from countries such as Northern Africa, of legal immigration from Eastern Europe, and of ongoing family formation migration-it remains amazing that research in this field continues to be an intellectually interesting and productive field, even in a period in which funding is more difficult. Again, this issue includes contributions from different countries covering different European regions. The field remains challenging because of several reasons.

Researchers are often confronted with unexpected, even contradictory results. For example, the perceived health of the native Greek population is not better than that of the immigrant Albanian population (see for e.g., Lahana et al. 2010). Also, mental disorders were not more prevalent among family reunification migrants (Norredam et al. 2010). These results call for further clarification.

A lot of progress is still possible in the explanation of differences in health, health care use, and quality of care between native and non-native populations. Still too often, studies are descriptive rather than explanatory. The limited advancement may be partly the result of less funding opportunities hampering new and adequate data collection. Nevertheless, researchers themselves may contribute more to improvement.

To start with, the vocabulary regarding migrant and ethnic minority health should be more clearly addressed (Nielsen and Krasnik 2010). Most of the research, certainly in Western Europe, pertains to migrant populations,

\section{Foets $(\bowtie)$}

Erasmus University of Rotterdam, Health Policy and Management, PO box 1738, 3000 DR, Rotterdam, The Netherlands

e-mail: foets@bmg.eur.nl whereas research in Eastern Europe focuses on the Roma population. In Western Europe the health, and, less frequently, the health care use and the quality of the care migrants receive, are compared to that of the native i.e., non-migrant population. This differs from research in the United States, where so-called racial groups (such as African Americans, Hispanics, etc.), are compared with the 'white population'. This difference relates to the relatively recent modern immigration history of Western Europe. Without elaborating on the broad discussion regarding terminology (see e.g., Lee 2009), researchers should be explicit whether their study population consists of migrants and eventually of their immediate descendants (second generation), or of broader ethnic categories. Fortunately, most contributions to this issue are remarkably clear. Sometimes, studies distinguish between groups based on the nationality criterion (e.g., Bollini et al, this issue). Migrants may take the nationality of the country in which they reside, which makes the groups under consideration heterogeneous (Rafnsson and Bhopal 2009). A clear definition of the populations under study not only contributes to a better understanding by the readers, but may also help to further direct the research in the explanation of eventual disadvantages.

Besides genetic explanations, and the healthy migrant effect, explanations are often and justly sought in socioeconomic differences. Also other mechanisms should be considered that contribute to differences, to start with the migration experiences, including discrimination, as well as cultural mechanisms. The cultural distance between recent migrants and so-called ethnic groups residing for many generations within a country may be quite different.

To gain insight into acculturation processes is not easy. Further distinguishing between first and second generation migrants is a first step. This is increasingly important 
because the second generation in Europe is growing. Such a distinction is still the exception (e.g., Nielsen and Krasnik 2010). It may shed some light on the question to what degree disadvantage diminishes in the course of time under influence of acculturation processes. In this issue, a German study investigated the differences in health care use between immigrants (first generation) and the second generation (Wengler, this issue). This distinction may also inform us on a potential increase of disquieting differences, e.g., the increase of tobacco use in the second generation (Reeske et al. 2009).

Other distinctions between the migrant groups under study may also contribute to a better understanding, such as migration motives (Norredam et al. 2010) and legal status (Pikhart et al. 2010). In this issue it appeared that the specific country of origin also matters (e.g., Sanz et al, this issue). Attention for the possible role of the place to which persons migrate was already asked (Agyemang et al. 2010). The German study mentioned above, expands on this topic by showing that Turkish immigrants in former Eastern Germany perceived their health better than native Germans, while those in Western Germany did not differ much from native Germans (Wengler, this issue).

As the research is often based on routinely collected data, or on data collected for primarily other purposes, often no information is available on migration and cultural mechanisms possibly contributing to differences. Better cooperation between social scientists and epidemiologists could lead to improvement by contributing to better hypotheses, and to a more adequate measurement of these social mechanisms.

Also regarding socioeconomic explanations, unfortunately, researchers sometimes have to rely on available indicators, rather than on indicators deliberately chosen on the basis of hypotheses (Stronks and Kunst 2009). Possibly this contributes to the sometimes ambiguous results. Sometimes it explains most of the ethnic differences, but often only part of it. For example, educational level may be an important indicator when the hypothesis is that knowledge is an important factor explaining differences in health care use, income level may be important when not all citizens are insured and/or when out-of-pockets payments are often required.
Even when accounting the analysis for socioeconomic position, it is seldom in itself the explanation of health differences. Research should further investigate how socioeconomic factors, as well as cultural and migration characteristics affect health by means of more proximate (intermediate) determinants such as the life style and environmental factors, which may differ between migrant and native populations.

Finally, inclusion of the new groups of immigrants mentioned at the beginning of this editorial is still exceptional. Since the size of these groups is increasing, future studies should not overlook these groups. Several circumstances, including their legal and health insurance status, make them potentially at risk for adverse health outcomes and less access to health care facilities.

\section{References}

Agyemang C, Kunst AE, Stronks K (2010) Ethnic inequalities in health: does it matter where you have migrated to? Ethn Health $15: 216-218$

Lahana E, Pappa E, Niakas D (2010) The impact of ethnicity, place of residence and socioeconomic status on health-related quality of life: results from a Greek health survey. Int J Public Health $55: 391-400$

Lee C (2009) "Race" and "ethnicity" in biomedical research: how do scientists construct and explain differences in health? Soc Sci Med 68:1183-1190

Nielsen SS, Krasnik A (2010) Poorer self-perceived health among migrants and ethnic minorities versus the majority population in Europe: a systematic review. Int J Public Health 55:357-371

Norredam M, Garcia-Lopez A, Keiding N, Krasnik A (2010) Risk of mental disorders in family reunification migrants and native Danes: a register-based historically prospective cohort study. Int J Public Health 55:413-419

Pikhart H, Drbohlav D, Dzurova D (2010) The self-reported health of legal and illegal/irregular immigrants in the Czech Republic. Int J Public Health 55:401-411

Rafnsson SB, Bhopal RS (2009) Large-scale epidemiological data on cardiovascular diseases and diabetes in migrant and ethnic minority groups in Europe. Eur J Public Health 19:484-491

Reeske A, Spallek J, Razum O (2009) Changes in smoking prevalence among first- and second-generation Turkish migrants in Germany: an analysis of the 2005 Microcensus. Int J Equity Health 8:26

Stronks K, Kunst AE (2009) The complex interrelationship between ethnic and socio-economic inequalities in health. J Public Health $31: 324-325$ 